\title{
Psychological and social aspects of infertility in men: an overview of the evidence and implications for psychologically informed clinical care and future research
}

\author{
Jane RW Fisher and Karin Hammarberg
}

Research concerning the psychosocial aspects of infertility and infertility treatment focuses more often on women than men. The aim of this review was to synthesize the English-language evidence related to the psychological and social aspects of infertility in men and discuss the implications of these reports for clinical care and future research. A structured search identified 73 studies that reported data concerning the desire for fatherhood and the psychological and social aspects of diagnosis, assisted reproductive technology (ART) treatment and unsuccessful treatment among men with fertility difficulties. The studies are diverse in conceptualisation, design, setting and data collection, but the findings were reasonably consistent. These studies indicated that fertile and infertile childless men of reproductive age have desires to experience parenthood that are similar to those of their female counterparts; in addition, diagnosis and initiation of treatment are associated with elevated infertility-specific anxiety, and unsuccessful treatment can lead to a state of lasting sadness. However, rates of clinically significant mental health problems among this patient population are no higher than in the general population. Infertile men who are socially isolated, have an avoidant coping style and appraise stressful events as overwhelming, are more vulnerable to severe anxiety than men without these characteristics. Men prefer oral to written treatment information and prefer to receive emotional support from infertility clinicians rather than from mental health professionals, self-help support groups or friends. Nevertheless, structured, facilitated psycho-educational groups that are didactic but permit informal sharing of experiences might be beneficial. There are gaps in knowledge about factors governing seeking, persisting with and deciding to cease treatment; experiences of invasive procedures; parenting after assisted conception; adoption and infertility-related grief and shame among men. Few resource-constrained countries have any data concerning male experiences of infertility.

Asian Journal of Andrology (2012) 14, 121-129; doi:10.1038/aja.2011.72; published online 19 December 2011

Keywords: assisted reproductive technologies; male infertility; psychologically-informed clinical care; psychosocial aspects

\section{INTRODUCTION}

In high-income countries, approximately $15 \%$ of heterosexual couples experience difficulties conceiving when pregnancy is desired, and in up to half of these couples, infertility is attributable to the male partner. ${ }^{1}$ In the world's resource-constrained low and lower-middle income countries, the prevalence of infertility in couples is thought to be higher because of undetected and untreated reproductive tract infections. ${ }^{2}$ Men can be affected by infertility in several ways: through receiving a diagnosis of their own infertility, through being the partner of a woman who is infertile or through being part of a couple with unexplained infertility. Although the psychological and social aspects of infertility, fertility treatment with assisted reproductive technologies (ARTs) and infertility-related childlessness have been investigated comprehensively in women, the psychosocial consequences of infertility for men are less well understood. ${ }^{3}$

The aim of this paper was to synthesize the existing evidence concerning the psychosocial aspects of male-related infertility and explore the implications of these studies for comprehensive clinical care and future research.

\section{MATERIALS AND METHODS}

A structured literature search was conducted to identify Englishlanguage studies that investigated the short- and long-term psychological and social aspects of infertility and ART treatment in infertile men. Studies published prior to February 2011 were located by an electronic search using the CINAHL, Psych Info, Medline, Ref Man and Web of Science databases. The search terms used included 'male', 'men', 'man', 'masculine', 'infertility', 'sterility', 'sexual*', 'psychological phenomena', 'emotional', 'mental health', 'stress disorder', 'adjustment disorder', 'depression' and 'anxiety'. The titles and abstracts were reviewed, and the papers that met the inclusion criteria were retrieved in full. Reference lists of all potentially eligible studies were checked to identify any other studies not retrieved by the electronic search.

\section{RESULTS}

Of the 92 papers identified in the search, 19 addressing chronic illness and other risks to male fertility, sperm banking prior to cancer treatment, treatment for sexual dysfunction and desire for multiple pregnancies were excluded. In total, 73 papers met the inclusion criteria for 
investigating or reviewing evidence concerning the desire for fatherhood or the nature and prevalence of psychological responses to and social consequences of infertility and associated treatment in men.

\section{Desire and motivation for fatherhood}

The desire to have a child is determined by multiple factors, including age, marital status, parity, gender, culture, religious beliefs and the degree of reproductive autonomy and access to contraception in a particular setting. ${ }^{4}$ Stereotypically, women are presumed to desire children and therefore to experience grief when the life goal of motherhood is unrealized, but men, having more diverse life opportunities, have been described as being 'disappointed but not devastated' by the inability to have a child. ${ }^{5}$

There are few population-based investigations of the desire to have children among men. Attitudes and motives influencing the desire to have or not to have children were examined in a survey in Germany of 1580 people aged $14-50$ (mean: $34.8 \pm 9.6$ ) years of whom $69 \%$ already had at least one child. ${ }^{6}$ Overall, among childless participants, more women $(45.9 \%)$ than men $(34.1 \%)$ currently desired a child, but the desire was equal among childless women and men aged 31-40 years (49\%). In both men and women, this sentiment was linked with wishes to create new life, form a household and experience love and was lessened by financial concerns. A comparable survey in England ${ }^{7}$ investigated the intentions and motivations for parenthood in 874 white, married, childless couples (393 men and 481 women) aged $32.9 \pm 4.5$ years. Younger individuals who had been married for a shorter time were the most likely to desire a child, and while $15 \%$ were unsure, $40.5 \%$ definitely intended to have children in the future. Unlike women, men did not report a biological drive for fatherhood and were more likely than women to identify continuation of the family name and the pleasure of having a child as reasons to reproduce. However, there were no overall differences between women and men in the intention to have a child.

The desire for fatherhood has also been investigated among men diagnosed as infertile. Edelmann et al. ${ }^{8}$ conducted a postal survey of emotional distress among 205 couples belonging to the UK National Association for the Childless in which the male partner was infertile. On average, women reported more psychological distress on a mood adjective checklist than did men, but the scores from both groups were higher than the average score for the overall UK population. This distress might have influenced the decision to join a self-help support group, but nevertheless suggested that men do not experience infertility as merely 'disappointing'. Dyer et al. ${ }^{9}$ used a checklist to assess the nature and intensity of motives for having a child among 50 couples attending public infertility treatment clinics in South Africa. The researchers found that the most commonly cited motives in men and women were to enhance happiness, experience parenthood and increase well-being. This study also noted that men and women desired children with similar intensities.

In a study of long-term outcomes, Fisher et al. ${ }^{10}$ surveyed attitudes towards parenthood in a sample of 112/276 (41\%) Australian men 5 years after receiving infertility diagnoses. Of these participants, $84 \%$ desired parenthood as much as their partners did. Fewer than half agreed with the Meaning of Parenthood Scale ${ }^{8}$ item that it would be more disappointing for a woman than a man not to have a child, and only $10 \%$ agreed that fertility demonstrated through fatherhood reflected masculinity. In the Netherlands, ${ }^{11}$ 108/164 infertile couples who had not become parents and for whom the interval since treatment initiation was on average 8.6 years were surveyed. In response to the parenthood motivation checklist, men were less likely than women to 'think often' about having children, but they were equally likely $(86 \%)$ to want a child and to identify happiness as the main motive for seeking parenthood. In this cohort, $62 \%$ of men reported that their desire to have children was equal to that of their partner's, and $8 \%$ stated a stronger desire than their respective partners.

\section{Anthropological theories of masculinity and reproduction}

Dudgeon and Inhorn ${ }^{12}$ concluded in a review of the biological and cultural anthropological theories of masculinity and human reproduction that infertility is potentially humiliating and emasculating to men, has a profound adverse impact on masculinity and is more stigmatizing for men than it is for women. The authors argue that men can conflate infertility, virility and sexual potency, which can therefore lead to perceived personal inadequacy. Gannon et al. ${ }^{13}$ conducted a discourse analysis of the national broadsheet newspaper reports of UK sperm count declines during 1992-1998 to evaluate how infertility and masculinity are represented and constructed in the media. They argued that in contemporary Western societies, stereotyped masculinity denies vulnerability, promotes an appearance of toughness and emotional control, minimizes the need for assistance from others and suggests a preoccupation with sex, which leads male infertility to be conflated with impotence. These approaches, which involve observation, investigation of small groups and examination of public media, do not collect systematic evidence from representative samples and, while they advance theory and might reflect popular opinion, cannot be generalized to individuals affected by fertility difficulties.

\section{Psychological reactions to infertility diagnoses}

Another body of research has used more systematic and duplicable methods to investigate the psychological consequences of being diagnosed as infertile or being a member of an infertile couple. Most studies have focused on women; however, some have assessed both partners in couples being investigated for fertility difficulties, and a small group have focused specifically on the experiences and needs of men. Many dimensions of psychological functioning after diagnosis have been investigated, including the consequences for mood, identity, self-esteem and quality of life. Some reports also examined the interactions between mood and personality variously conceptualized as coping style, capacity for emotional self-regulation, tendency to appraise situations as stressful and locus of control. Most studies have used self-report questionnaires including both standardized psychometric measures and study-specific questions.

Investigations in which the cause of infertility was not considered. Prospective $^{14-17}$ and cross-sectional ${ }^{18-20}$ studies have assessed psychological functioning in men at diagnosis or immediately prior to ART treatment. In broad terms, these sought to elucidate the nature of psychological distress; whether there were differences in psychological symptoms, most commonly depression and anxiety or quality of life between men and women, whether rates of clinically significant symptoms exceeded population prevalence and whether risk factors for, or correlates of, mental health problems could be identified. Most studies compared data from consecutively-recruited cohorts of men, women or couples attending clinical services, and some authors also made comparisons with published population norms. While this group of studies included people affected by fertility difficulties, none reported the psychological outcomes of infertility. Chachamovich et al. ${ }^{21}$ conducted a systematic review of 14 studies investigating the quality of life 'in infertility', of which nine compared both men and women in infertile couples. They described these patients as 'infertile men' but 
did not provide supporting evidence for this assertion. These authors concluded that in general, the quality of life reported by the infertile men was not seriously adversely affected, but there were cultural variations. The studies that assessed psychological functioning in infertile men directly appeared to reach different conclusions.

All studies in which men and women were compared analysed data presuming that the groups were independent of each other, and no study controlled for clustering effects within couples that can alter effect sizes. Nevertheless, a consistent pattern emerged. At initiation of treatment, 113 Australian men had lower mean depression (Centre for Epidemiologic Studies-Depression Scale: ${ }^{22} 6.3 \pm 5.7$ versus 9.1 \pm 7.9 ) and anxiety scores than women (State Trait Anxiety Inventory $(\mathrm{STAI}):^{23} 34.6 \pm 8.1$ versus $\left.38.7 \pm 11.8\right)(P<0.001) .{ }^{15}$ Edelmann and Connolly ${ }^{16}$ found a similar pattern in 246 couples in England: the mean Beck Depression Inventory (BDI ${ }^{24}$ scores were lower among men than women $(4.06 \pm 4.59$ versus $5.84 \pm 4.98, P=0.01)$ as were STAI State Anxiety scores $(32.80 \pm 8.10$ versus $36.72 \pm 9.16, P<0.01$ ). Anderson, Sharpe et al. ${ }^{14}$ found that in 113 Scottish couples, $1.8 \%$ of men and $2.7 \%$ of women $(P=0.02)$ scored in the clinical range of $>10$ on the Hospital Anxiety and Depression Scale, Depression Subscale ${ }^{25}$ and that $9 \%$ of men and $26 \%$ of women $(P<0.001)$ had clinically significant anxiety symptoms (Hospital Anxiety and Depression Scale Anxiety Subscale $>10$ ). In the United States, Wichman et al..$^{20}$ found that fewer men than women reported at least mild depression (BDI score $>14 ; 3.8 \%$ versus $5.6 \%$ ) and anxiety (STAI State Anxiety score $>45 ; 8.8 \%$ versus $14.4 \%)(P<0.01)$ in a study of 162 couples.

Anxiety appeared to be specific to the situation of being infertile rather than generalized. Wichman et al. ${ }^{20}$ found that at least mild infertility-specific distress as assessed by a modified Impact of Events Scale ${ }^{26}$ was prevalent in both sexes with $50.3 \%$ of men and $66 \%$ of women $(P<0.001)$ reporting scores $>8$. In North America, Peterson et al. ${ }^{19}$ used the Fertility Problem Inventory ${ }^{27}$ to assess 'infertility stress' and found that Global Stress scores in 506 men $(114.5 \pm 28.3)$ were lower than those in 520 women $(128.9 \pm 35.2)$ $(P<0.01)$ prior to initiation of treatment. Anderson et al. ${ }^{14}$ found, using a study-specific measure, that men in infertile couples had lower levels than women of 'infertility related concerns' about life satisfaction, sexuality, self-esteem and social participation. Nevertheless, 25\% of men reported compromised life satisfaction. In Sweden, ${ }^{28}$ reactions to infertility were investigated in 91 couples prior to initiation of treatment using a translation of the Infertility Reaction Scale (Keye et al, unpublished data, 1984). Men were less likely than women to think about infertility, found it difficult to separate infertility from the rest of their lives or felt a sense of failure because of infertility. However, there were no differences between men and women in other measures, including feelings of guilt, finding that having a child was a major focus of life and finding that difficulty in conceiving a child was more difficult to bear than had been imagined. Edelmann and Connolly ${ }^{16}$ concluded that claims of men having fewer adverse reactions to infertility than their partners reflect stereotypes about the desire for parenthood. Additionally, although some responses might be gender-specific, both men and women have heightened psychological needs in response to this unanticipated adverse life event.

One major population survey ${ }^{18}$ investigated whether 2291 randomly selected 30 - to 44-year-old Finnish participants who had experienced infertility exhibited more severe or persistent mental health problems than those who had not experienced infertility. The 99 men (9\%) who reported infertility had the same rates of psychiatric illness, as assessed by the Composite International Diagnostic Interview, ${ }^{29}$ and of psychological symptoms on the General Health
Questionnaire- $12^{30}$ and the BDI as did the general population. Childless men who had experienced infertility had significantly lower subjectively appraised quality of life than men who were childless but had not experienced infertility, which was attributed to the degree of choice about this reproductive outcome. Beaurepaire et al. ${ }^{15}$ reported that more men at treatment initiation had 'clinically elevated' STAI State Anxiety scores indicating 'situational distress' than population norms (38\% versus $15 \%, P<0.001$ ), but fewer had depressive symptoms (Centre for Epidemiologic Studies-Depression Scale score $>16$ ) ( $4 \%$ versus $10 \%, P=0.03$ ). Similarly, Glover et al. ${ }^{31}$ assessed 109 'male sub-fertility clinic attendees' before and immediately following the first specialist consultation. They found that high anticipatory anxiety (50\% in the Hospital Anxiety and Depression Scale clinical range) and self-blame for infertility diminished, but that depressive feelings increased, perhaps related to their lowered personal estimates of pregnancy likelihood.

In Slovenia, the link between psychological factors and semen quality was assessed in 1076 men who were being evaluated for infertility. ${ }^{17}$ According to the Zung Anxiety Scale, ${ }^{32} 19.9 \%$ of these patients scored in the clinical range $\geqslant 34$, but on the World Health Organization Wellbeing Index (WHO-5), ${ }^{33}$ only $1.8 \%$ scored $\leqslant 5$, indicating that these men were possibly depressed. Higher rates of cigarette smoking, alcohol use and sexual difficulties were found among men with Zung Anxiety Scale scores $\geqslant 34$. Edelmann and Connolly ${ }^{16}$ reported that men's scores on the STAI and the General Health Questionnaire were, on average, indistinguishable from or lower than population norms, and Holter et al. ${ }^{34}$ observed that 166 Swedish men assessed by the Personal General Well-being Index ${ }^{35}$ were in 'generally good psychological health' with no differences as compared with population norms. Overall, with the exception of acute and situation-specific anxiety, there appears to be a generally low prevalence of clinically significant psychological symptoms compared with community norms among infertile men.

Investigations in which the cause of infertility was considered. Another group of studies used methods comparable to those described above but made comparisons between groups of men and of couples classified on the basis of the cause of infertility.

Nachtigall et al. ${ }^{36}$ investigated 36 volunteer couples undergoing infertility treatment in America using snowball sampling and in-depth interviews. The authors assessed whether emotional responses varied by sex-specific diagnoses. They found that men with male factor infertility experienced more 'negative emotional responses', including a sense of loss, stigma and reduced self-esteem, than men whose partners were infertile or who were in couples in which fertility difficulties were unexplained. They concluded that men's responses to infertility approximated those of women only when the infertility was attributable to a male factor.

Other studies used surveys and standardized measures to assess psychological outcomes of infertility. Data from the Copenhagen Multi-Centre Psychosocial Infertility (COMPI) research programme revealed no differences between men's scores on the Fertility Problem Stress Inventory ${ }^{37}$ or the Mental Health Component of the Short Form Health Survey (SF-36) ${ }^{38}$ at initiation of treatment whether infertility was attributable to male, female, mixed or unexplained causes. ${ }^{39}$ Lee et al. ${ }^{40}$ used the same classification system for 138 couples presenting for treatment in Taiwan, China. They assessed psychological functioning using the Chinese Infertility Questionnaire ${ }^{41}$ and found no differences in men's self-esteem or guilt between groups. Holter et al. ${ }^{34}$ also found no differences between men's PWGB psychological well-being 
scores according to cause of infertility among 200 men in Sweden. In America, ${ }^{42}$ a study-specific measure of the impact of infertility was completed by 357 men of infertile couples from eight clinics (12\% with an isolated male factor, $16 \%$ with male and female factors and $25 \%$ with unexplained causes of fertility). When other factors were controlled, men with male factor infertility had poorer 'personal quality of life' than men in other couples. In Canada, Dhillon et al. ${ }^{43}$ compared groups of men who were partners of currently pregnant women and were presumed to be fertile, infertile with oligoasthenospermia or part of a couple with unexplained infertility. There were no differences in the mean scores for measures of depression, anxiety, anger or selfesteem among these groups. However, on the Family Inventory of Life Events and Changes, ${ }^{44}$ which assesses the impact of current stressful events on mood, men whose partners were pregnant had significantly higher psychological distress than either of the infertile groups. Yet, all scores were in the moderate range reflecting 'typical levels of family stress'.

In Poland, Drosdzol and Skrzypulex ${ }^{45}$ compared psychological functioning in 188 men and 206 women in couples aged 20-45 years old who attended an infertility clinic with that of 190 couples of similar age with at least one child in which the woman was attending a general gynaecology clinic. Men in the infertile couples had higher levels of depressive symptoms (BDI score $5.1 \pm 6.6$ versus $3.7 \pm 4.5, P=0.048$ ) and anxiety (Beck Anxiety Inventory score $6.1 \pm 7.7$ versus $4.5 \pm 6.0$, $P=0.02)$ that did fertile men. More infertile than fertile men had at least mild clinically significant symptoms (15.6\% versus $11.6 \%$, BDI $>10$ and $4.7 \%$ versus $2.1 \%$, Beck Anxiety Inventory $>21$ ); however, in most cases, symptoms were mild to moderate, and in no cases were symptoms severe. Tüzer et al. ${ }^{46}$ assessed 60 couples with primary infertility who had experienced at least 3 years of fertility treatment in Turkey. On average, women in the infertile couples in both of these studies had higher symptom scores than men, but the differences were not significant. Anxiety related to treatment procedures increased among men, but not women, and was interpreted as desensitisation associated with repeated exposure to intrusive treatments in women. ${ }^{46}$

Psychological factors associated with infertility distress in men. Some studies sought to identify whether personality characteristics or attitudes influenced male adjustment to infertility. Band et al. ${ }^{47}$ used the Perceived Stress Scale ${ }^{48}$ and the Ways of Coping Questionnaire ${ }^{49}$ to assess 51/130 (39\%) men with male factor infertility attending a clinic in England. More severe depressive and anxious symptoms were associated with an avoidant coping style, a 'tendency to appraise situations as stressful' and failure to seek social support.

With similar aims, Beaurepaire et al. ${ }^{15}$ reported that, in general, men had a more internal locus of control, reflecting a greater sense of agency over events, and less self-blame and guilt about infertility than did women. Their locus of control was comparable to community norms. Peterson et al. ${ }^{19}$ also used the Ways of Coping Questionnaire and found that men used the following strategies more commonly than women did: 'distancing', or making light of the situation; 'self-controlling', or keeping feelings about infertility contained and not permitting them to govern daily life; and 'planful problemsolving', or seeking information and solutions. Men and women used 'seeking social support' or talking to friends and professionals at the same level. For both men and women, using a problem-solving approach and seeking social support were associated with lower levels of 'infertility stress'. Anderson et al. ${ }^{14}$ used a structured study-specific questionnaire to assess 'concerns' and found that men in infertile couples were less likely than women to experience self-blame and reduced self-esteem and were also less likely to avoid seeing friends. In Sweden, Hjelmstedt et al. ${ }^{28}$ found that significantly more men (approximately 50\%) than women had not shared their infertility problems with another person. In contrast to other reports, in this study, men who had an information-seeking adaptive style were more distressed than those who tended to avoid information. This result was interpreted as reflecting the inherent frustrations of being in a situation that is poorly understood and in which assured treatments are not available.

Jordan and Revenson ${ }^{50}$ conducted a meta-analysis of six crosssectional studies published between 1966 and 1995 that had examined coping strategies after infertility diagnosis using standardized measures in men and women. They concluded that, overall, there were more similarities than differences among the eight assessed strategies. However, men used social support seeking, avoidance and positive reappraisal of the situation less than did women.

\section{Impacts of infertility on men in resource-constrained countries} Most men of reproductive age live in the world's low- and lowermiddle-income resource-constrained countries. Many of these have a public policy focus on population control and less recognition of the needs of, or service provision for, people with fertility difficulties. ${ }^{2}$ Inhorn $^{2}$ argues that 'in addition to the right to control fertility, reproductive rights must encompass the right to facilitate fertility when [it] is threatened'. Inhorn also warns ${ }^{51}$ that in Muslim communities, religious beliefs make infertility assessment and treatment particularly difficult for men because masturbation is proscribed. Procreation is highly valued in many of these settings, and infertility contributes to substantial suffering, including the loss of the security of marital relationships, social stigma and ostracisation. The limited understanding of the mechanisms of human reproduction among people in these countries means that women are frequently held responsible for infertility and bear the social costs when conception does not occur and children are not born. ${ }^{52}$ Umeora et al. ${ }^{53}$ found that, of 138 female consultations for infertility, only $63 \%$ of patients' husbands were ultimately prepared to attend the clinic. Of these, $17.5 \%$ were 'very reluctant and required much persuasion to undergo seminal fluid evaluation' and $12.6 \%$ refused. Most husbands believed that they could not be responsible for infertility, and others were concerned that the sample could be used for witchcraft or rituals.

In a major investigation of the sociocultural consequences of infertility in Rwanda, 312 women who presented with failure to conceive, 254 of their partners and fertile control groups of similar sizes were surveyed; focus group discussions including 20 men each were also conducted. ${ }^{54,55}$ Stigmatisation, chronic suffering and misattribution of characteristics (e.g., being accused of witchcraft or bringing bad luck) were widespread among participants. While men in the focus groups described a loss associated with lack of continuation of the family and that a life without children was less fulfilling, few agreed with the stereotype that masculinity was confirmed by fathering a child. Male and female focus group participants were surprised to learn about male factor infertility, having believed that infertility was always attributable to women. Although participants suggested that men would generally separate from a woman who had not had a child, few thought that women would leave a male partner who was infertile. The general understanding of the causes of infertility was low, and many participants reported having sought assistance from traditional healers. Men were more likely to have sought treatment in the formal medical sector if they had higher incomes, were married and had been infertile for at least 5 years. ${ }^{54}$ Similarly, in Zimbabwe, 
Folkvord et al. ${ }^{56}$ investigated 311 men identified as infertile at a family planning clinic. Most men (70\%) 'felt uncomfortable about being infertile', with one-third of participants reporting symptoms of at least mild depression and sleeping difficulties. Many described interpersonal difficulties, with tension in their relationships with their partners and other family members. Superstitious beliefs about fertility difficulties, for example, that their wives' 'wombs were tired and turned against the sperm', were common, and $80 \%$ had consulted traditional healers before attending the clinic. Nieuwenhuis et al. ${ }^{57}$ drew similar conclusions from in-depth interviews with seven infertile men in Nigeria but found that in addition to beliefs about 'powers of darkness or Juju' or being cursed by God, 'immorality' was widely regarded as a cause of infertility. Few participants in the study by Folkvord et al. ${ }^{56}$ were prepared to consider the use of donor gametes because of beliefs that ancestral lines would be damaged by 'alien sperm'. Sperm donation within the family was more acceptable.

Dyer et al. ${ }^{58}$ conducted a qualitative study of 27 men attending a public access fertility clinic in South Africa for the first time and also found that these patients had limited reproductive health knowledge and attributed infertility to a 'dirty womb', ancestral disapproval or witchcraft invoked by a jealous person. A later study in the same setting ${ }^{59}$ assessed psychological distress in 120 men from infertile couples and 120 men attending antenatal clinics with a pregnant partner using the Symptom Checklist $90 .^{60}$ Men from the infertile couples had significantly higher scores (indicating greater distress) on all symptom dimensions than fertile did men, but the mean scores from this group were all within normal ranges.

\section{Consequences of infertility for intimate partner relationships and sexual functioning}

Some investigations sought to elucidate the consequences of infertility on the quality of relationships between intimate partners. Most studies focused on the sexual aspects and fewer focused on the emotional and communicative aspects of these relationships, and in general, comparisons on the basis of whether infertility was attributable to male or female factors were not described. ${ }^{61}$

In Germany, ${ }^{62}$ current and prediagnosis recollections of intercourse frequency and sexual satisfaction were assessed in 68 consecutively recruited men with male factor infertility. Frequency of intercourse was lower among those with relationships (and awareness of infertility) of longer duration, but overall, there were high levels of current sexual satisfaction and no differences between those with longer or shorter interval since diagnosis. Using the same measures, Ramezanzadeh et al. ${ }^{63}$ investigated 200 men who were recruited consecutively while attending an infertility clinic in Iran. Although there were generally high levels of sexual satisfaction, $41.5 \%$ reported at least some reduction in desire and $52.5 \%$ in satisfaction since diagnosis. Neither age nor cause of infertility was related to sexual satisfaction, but it was negatively related $(P<0.01)$ to duration of time since diagnosis. In a study by Smith et al. ${ }^{42}$ for men with male factor infertility or in couples with unexplained infertility, there were lower levels of sexual quality of life, assessed by enjoyment, sense of attractiveness to the intimate partner and intrusiveness of thoughts about fertility problems and wanting a child during intercourse. In the study by Tüzer et al. ${ }^{46}$ in Turkey, fewer men (20\%) than women (44\%) reported that sexual interest had decreased since infertility diagnoses. Men with male factor infertility had higher scores on the Dyadic Adjustment Scale Affectional Expression ${ }^{64}$ subscale than women, which was interpreted as indicating that men in this situation feel the need to give their partners compensatory affection. In the Australian long-term follow-up study, ${ }^{10,65} 25 \%$ of participants regarded infertility as having had a generally negative effect on their relationships with their intimate partners, and $32 \%$ reported that sexual satisfaction had diminished.

The baseline and 12-month follow-up phase of the Danish COMPI study ${ }^{66}$ assessed 'marital benefit' or the extent to which childlessness had strengthened the relationship among those who had not experienced a pregnancy. At baseline, approximately $50 \%$ of the 1081 male respondents (significantly fewer $(P<0.002)$ than among female respondents) agreed that childlessness had marital benefits. Men who used active coping strategies (expression of feelings, seeking of advice) could make meaning of the experience and did not keep their infertility secret described greater marital benefits. Hjelmstedt et al. ${ }^{28}$ found that in men, the experience of infertility was associated with a sense of injustice and increased concern about partner well-being but that infertility led to enhanced personal maturity and a closer marital relationship.

\section{Male experiences of infertility treatment}

A systematic review of research concerning patients' perspectives on fertility care ${ }^{67}$ found that very few studies $(3 / 51)$ had focused specifically on men's experiences. The main findings were not disaggregated to distinguish men's accounts, but it was argued that the relevant dimensions applied to all infertility treatment consumers and included the following parameters: access to services; respect for values, choices and needs; continuity and coordination of care; appropriate information and education; physical comfort; support to reduce anxiety; and involvement of partners. The authors concluded that there was a dearth of evidence regarding men's perceptions of care, particularly with regard to invasive procedures. In broad terms, the available research has focused on satisfaction with technical and procedural aspects of care and perceptions of the quality of emotional care.

In the Netherlands, open-ended questions were used in face-to-face interviews to explore the experiences of 17 men regarding their testicular biopsy, and telephone interviews were completed with an additional 15 men to appraise their satisfaction with the care received. ${ }^{68}$ The researchers concluded that in addition to technical skill, highquality care was characterized by friendly, empathic staff attitudes; provision of treatment stage-specific oral and written information; privacy, including access to a waiting space separate from that used by pregnant couples; and staff support during procedures. A separate study from the Netherlands ${ }^{69}$ used focus groups to develop a questionnaire concerning clinical services, which was then completed by $286(78 \%)$ women and 280 (76\%) men from 369 couples at 13 clinics. Clinical strengths included respect, autonomy and partner involvement, but the most commonly identified weaknesses were lack of emotional support and continuity of care.

Pook et al. ${ }^{70}$ assessed psychological distress using their Infertility Distress Scale in 113 German men attending clinics for 'infertility workup' and followed up with 60 patients 4 months later. They concluded that initiating treatment was associated with a decline in distress but only in men attending for first consultations and not for those with longstanding difficulties. In a subsequent study using the same measure ${ }^{71}$ in men who had repeat infertility assessment visits at least 6 months apart, these authors found that distress increased during this time interval in men who had been undergoing prolonged treatment or who had experienced treatment failure. Peronace et al. ${ }^{39}$ followed 256 men in Denmark who were assessed prior to treatment initiation and after 12 months of unsuccessful treatment. Regardless of the cause 
of infertility, distress increased significantly when treatment was unsuccessful. The 12-month follow-up COMPI data (1934 participants, 909 men from five clinics) revealed a generally high satisfaction with both technical and psychosocial aspects of care and no differences between men and women, but satisfaction was the highest among those who had conceived. ${ }^{72}$ In contrast, study-specific Australian data concerning the perception of the quality of infertility-related health care among 112/276 (41\%) men diagnosed as infertile 5 years earlier revealed high satisfaction with medical and nursing care irrespective of whether treatment had resulted in fatherhood. ${ }^{65}$

\section{Needs for social and professional support}

A series of studies assessed men's perceptions of their needs for informal and formal support during investigations for infertility, adjustment to diagnosis and treatment.

Informal social support. Some reports investigated the extent to which men affected by infertility confided in and sought additional support from family members and friends. A Swedish study ${ }^{28}$ found that for men, common sources of support included friends (38\%) and their own mothers $(27 \%)$ and fathers $(23 \%)$, but a large proportion $(47.3 \%)$ had not confided in anyone other than their spouse. In Italy, Agostini et al. ${ }^{73}$ conducted a cohort study of $83 / 161$ (51\%) couples from treatment initiation to 1 month after embryo transfer and investigated perceived social support using the Multidimensional Scale of Perceived Social Support. ${ }^{74}$ At all time points studied, men were found to have less social support and to be less likely to discuss infertility and treatment with others than women. In Taiwan, China, in-depth interviews with 30 men diagnosed as infertile revealed the tension between the need for support and that of preserving 'face'. In general, shame about the diagnosis constrained disclosure to anyone apart from their wives. ${ }^{75}$

Malik and Coulson ${ }^{76}$ investigated the extent to which the internet was used as a resource for information and emotional support, postulating that availability, accessibility and anonymity would make it especially acceptable to men. They undertook a thematic analysis of 728 messages posted by men on an online infertility support group message board. They concluded that men experience 'emotional anguish' as a result of infertility, but that this needed to be suppressed in order to protect their partners and that online support groups, which do not involve face-to-face encounters, may be particularly useful locations for men to confide in others.

Formal support from infertility clinicians and mental health professionals. In broad terms, two approaches were taken to investigate the need for information and emotional support from professionals: preferences for and satisfaction with routine clinical care and utilisation of specialist mental health care. In the United States, Brucker and McKenry ${ }^{77}$ developed a study-specific measure to assess how well needs for information and emotional support had been met by medical and nursing staff among 120/686 (17.5\%) members of an infertility support group (47 men). For men, but not women, a higher level of perceived support from health care professionals was associated with lower levels of stress and anxiety but not depression. A separate survey by Hammarberg et $a .^{65}$ assessed preferred sources of infertility-related information and emotional support. Similar to the group in the study by Glover et al., ${ }^{31}$ the patients' primary preference was for information to be provided via face-to-face discussions with clinic staff. The most helpful and valued sources of support were patients' partners and clinic staff and the least preferred were friends and support groups.
In France, Laffont and Edelmann ${ }^{78}$ surveyed 218 people (101 men) who were undergoing treatment using a study-specific questionnaire about perceived and desired support. Most men had told their parents and friends about participating in infertility treatment, and $58 \%$ had discussed treatment outcomes with a doctor. Overall, 66\% thought that psychological services including individual (66\%), couple (61\%) and group (44\%) counselling should be available especially after a failed treatment cycle. However, fewer men (10\%) than women $(21 \%)(P<0.05)$ had actually talked to a psychologist, suggesting that there are significant barriers to the utilisation of such services.

Schmidt et al. ${ }^{79}$ investigated consumer opinions at the outset of treatment concerning the need for 'patient-centred' or routine empathic supportive care and psychological care provided by a mental health practitioner in 2250 (1081 men) COMPI participants. While most participants identified communication of test results and discussion of treatment options as important, fewer men than women wanted this information in writing. Both men and women valued patient-centred care, including explicit concern for emotional wellbeing. Patients desired treatment models within routine care rather than referrals to information and support services for childless people or written information about mental health. Only $8.9 \%$ of men indicated that they would attend a course about childlessness, $7.5 \%$ a psychologist, $5.7 \%$ a sex therapist and $4.1 \%$ a support group.

Boivin et al. ${ }^{80}$ investigated barriers to the use of counselling services in a group being treated for infertility ( 49 men) in England. For both men and women, the spouse was the most common source of support (57.1\%), and counsellors (6.1\%) and self-help groups (2.0\%) were the least common. The main factors preventing consultations with a counsellor included having sufficient support available from other people, financial costs, practical difficulties and awkwardness. The authors concluded that information about emotional factors should be made available through other media, including written material and documentaries.

Wischmann et al. ${ }^{81}$ used local measures to assess life satisfaction, desire for a child, personality and psychological symptoms in 564 German couples during their first infertility clinic visits. Overall, $34 \%$ (275 women and $243 \mathrm{men}$ ), approximately half of those who had indicated interest, actually participated in formal psychological counselling. Participation in counselling was most strongly predicted by distress at baseline in the female partner when compared with those who did not participate. Men who attended counselling had lower sexual satisfaction and a lower quality of intimate partner relationships at treatment initiation.

In contrast, Furman et al. ${ }^{82}$ assessed 284 low-income men receiving government-funded infertility treatment in Chile. In this service, at no cost to the individual, couple and group counselling is offered to all patients, and patients can self-refer. Group counselling is a limited series of four sessions with mixed didactic and interactive formats. Overall, 143 individuals participated in at least one form of counselling, most commonly attending groups as a couple; $43 \%$ of couples with male factor infertility but $23 \%$ with female factor infertility attended all sessions. While the high utilisation might have been attributable to cultural factors, the investigators considered that access to psychological services within the clinic and orientation-totreatment sessions, which emphasize the value of counselling for all patients, were critical. Groups were rated as 'highly useful' in increasing social connections and enhancing relationship between partners.

Long-term psychosocial aspects of infertility and fertility treatment The long-term psychosocial sequelae of infertility for men have been reported in three investigations. Throsby and Gill ${ }^{83}$ undertook 
discourse analysis using in-depth interviews with 41 people (13 men, all interviewed within couples) who had elected to cease treatment in England. All were interviewed at least 2 years after their last in vitro fertilisation treatment. The authors identified that while women's disclosures about infertility tended to attract support, men were more likely to have been subjected to banter and thoughtless comments, in particular about sexual technique and potency and especially in the workplace, all of which had constrained support-seeking. Infertility treatments were regarded with ambivalence both as valuable technologies that had great potential to bring scientific assistance to a 'natural' problem and as being uncomfortable and intrusive. Furthermore, these treatments were viewed as reducing men's capacity for agency because, apart from providing semen, they were generally excluded from active treatment. The inability to father a child had engendered feelings of humiliation and inadequacy, and men had felt obliged to set aside their emotional needs in order to 'be strong for her'.

Sherrod ${ }^{84}$ conducted in-depth interviews with 10 men 50 years of age and older who had not become biological fathers, six of whom due to male factor infertility. The author found that these participants had avoided disclosure or revelation of emotional distress to protect their own dignity and relationships and to prevent their partners from further suffering. This study concluded that this practice had impeded the development of a satisfying life without children.

The Australian long-term follow-up study of men diagnosed as infertile 5 years earlier ${ }^{10,65}$ assessed current life satisfaction, physical health and emotional well-being. Most participants (96\%) had pursued infertility treatment, and $87 \%$ were fathers. There were no differences from population norms with regard to quality of relationship with intimate partners (Intimate Bonds Measure ${ }^{85}$ ) or general satisfaction with life (Satisfaction with Life Scale ${ }^{86}$ ), and participants were in good physical health (SF-12 PCS score). ${ }^{87}$ However, when other factors were controlled, men who had not become fathers had significantly poorer mental health than those who were fathers (SF-12 MCS score), ${ }^{87}$ indicating a state of chronic sorrow or grief among those for whom parenthood had been an unrealized, but desired life goal. ${ }^{10}$

\section{DISCUSSION}

There has been less research about the experiences of men than of women affected by infertility, which probably reflects a similar pattern to the more limited research about men and fatherhood than women and motherhood. ${ }^{67,83}$ However, there is now a body of evidence that elucidates some of the psychological and social aspects of infertility for men. ${ }^{3}$ While the research has been undertaken in diverse settings using varied designs, sampling and recruitment strategies, and data sources, there is considerable consistency among the findings. We acknowledge that in limiting the search to the English-language literature and including only studies with an identified focus on men that evidence relevant to this review might have been overlooked. We also acknowledge that most of this evidence has been derived from individuals seeking treatment and that it does not elucidate the experiences of people who do not 'define their [in]ability to have a child as a problem'. ${ }^{3}$

The available evidence supports the assertion ${ }^{83}$ that normative assumptions about the importance of child bearing and rearing for women coupled with the focus of ART treatment on women's bodies have reduced the visibility and awareness of men's experiences of childlessness. These data suggest that independent of their partner's wishes, fertile and infertile men want to father children and experience fatherhood. Further, these men experience grief when this life goal is unrealized, which can become an enduring sadness if fertility treatment is unsuccessful. These studies also suggest that there is a disjunction between putative popular beliefs about the conflation of virility and fertility and individual men's experiences of these as separate aspects of their lives. In low-income settings, these issues are worsened by the lack of accessible services and limited knowledge of reproduction, including of risks to fertility.

It appears that infertility-specific anxiety is elevated in men at the initiation of diagnostic investigations, confirmation of diagnosis and during treatment, but the overall prevalence of clinically significant symptoms of depression and anxiety is no higher in these men than in the general population. Men might be more able to compartmentalize their emotions and to continue to participate in their professional lives without being preoccupied or disabled by anxiety. Men might also suspend their emotional needs to help with their partners' increased requirements for support. However, it is inaccurate to interpret this action as an indication that men do not experience distress and that empathy and encouragement are not wanted. There is some evidence that men who are socially isolated, have an avoidant style and appraise stressful events as overwhelming are particularly vulnerable to more severe anxiety.

In general, it appears that men do not readily share their increased needs with people other than their partners. Information about causes of infertility and treatment options and outcomes is sought from infertility practitioners with a preference for oral rather than written communication. With the exception of those attending infertility clinics in Chile, ${ }^{82}$ men prefer to receive relevant emotional support from infertility clinicians within routine care rather than from mental health professionals, self-help support groups or friends. Nevertheless, it is possible that structured, facilitated psycho-educational groups, which are didactic but permit informal sharing of experiences, would be beneficial. The exception appears to be the assistance needed to persuade men to use donor sperm, in particular in settings in which semen is donated anonymously and children will never have access to identifying donor information.

\section{IMPLICATIONS FOR CLINICAL PRACTICE}

These findings suggest that comprehensive clinical care within infertility services is of particular importance to the protection of emotional well-being among men affected by infertility. As men appear to be more likely to confide in and desire information and emotional support from infertility clinicians rather than from friends or mental health professionals, explicit assessment of the emotional well-being of men at the initial assessment and during treatment might be beneficial. ${ }^{31,65,77}$ The spontaneous disclosure of emotional needs and explicit support-seeking appear to be uncommon among men affected by infertility. Some investigators propose that the systematic assessment of mental health using psychometric questionnaires within assessment and treatment protocols would assist in the detection of psychological symptoms, but the acceptability and feasibility of these methods have not been established. ${ }^{77}$ If clinicians are willing, then an explicit enquiry using the statement and question method can be an effective clinical tool (e.g., 'I have met many men experiencing infertility, and they often feel sad, worried, embarrassed, lonely, etc.'; followed by the enquiry: 'Have you had any feelings of this kind?' or 'I would be interested to hear how you are feeling'). A first-line clinical strategy in which empathic responses are coupled with exploration about the people to whom the patients have disclosed concerns, what alternative sources of support might be considered and specific encouragement to pursue these sources has the potential to reduce social isolation and anxiety.

Referral to a mental health professional might assist the subgroup of men who have not disclosed their situation to anyone apart from their 
spouse and who appraise the situation as catastrophic, hopeless or overwhelming. It is also suggested that consultation with a mental health professional should be mandatory prior to using donor sperm. ${ }^{88}$

\section{IMPLICATIONS FOR FUTURE RESEARCH}

While there is an emerging body of evidence focused on the psychological and social aspects of infertility for men, significant knowledge gaps remain. ${ }^{3,84}$ As most studies recruited participants from clinical services, little is known about men who do not seek treatment. Among those who do pursue treatment, the factors that influence persistence with and decisions to discontinue treatment are unknown. The psychological aspects of treatment including experiences of invasive investigations or of witnessing their partners undergoing procedures have not been described. The factors governing the decisions to either become a parent through adoption or to live without children among men in couples who elect not to pursue infertility treatment are also unknown. Subfertile men's reactions when spontaneous conception occurs unexpectedly have not been studied. There is some evidence concerning female experiences of pregnancy and early parenthood after assisted conception, but none about men's reactions to and needs during these experiences.

Few studies reported whether male-specific cutoff scores were used to identify the prevalence of clinically significant psychological conditions, in particular anxiety and depression. However, comparisons with test norms indicate that apart from situation-specific anxiety, prevalence of depression and anxiety appears to be the same in men affected by infertility as in the general population. In order to understand men's needs more fully, other relevant dimensions of psychological functioning, including experiences of grief and shame, warrant systematic investigation.

There is a marked disparity in the availability of evidence concerning men's experiences of infertility and fertility treatment between high-income countries and the resource-constrained countries in which most men of reproductive age live, which constitutes a serious knowledge gap.

\section{COMPETING FINANCIAL INTERESTS}

The authors declare that they have no competing financial interests.

1 Skakkebaek N, Giwercman A, de Kretser D. Pathogenesis and management of male infertility. Lancet 1994; 343: 1473.

2 Inhorn MC. Right to assisted reproductive technology: overcoming infertility in lowresource countries. Int J Gynaecol Obst 2009; 106: 172-4.

3 Greil AL, Slauson-Blevins K, McQuillan J. The experience of infertility: a review of recent literature. Sociol Health IIIn 2010; 32: 140-62.

4 Hadley R, Hanley T. Involuntarily childless men and the desire for fatherhood. J Reprod Infant Psychol 2011; 29: 56-68.

5 Greil AL. Infertility and psychological distress: a critical review of the literature. Soc Sci Med 1997; 45: 1679-704.

6 Stöbel-Richter Y, Beutel ME, Finck C, Bräler E. The 'wish to have a child', childlessness and infertility in Germany. Hum Reprod 2005; 20: 2850-7.

7 Langdridge D, Sheeran P, Connolly K. Understanding the reasons for parenthood. J Reprod Infant Psychol 2005; 23: 121-33.

8 Edelmann RJ, Humphry M, Owens DJ. The meaning of parenthood and couples' reactions to male infertility. Br J Med Psychol 1994; 67: 291-9.

9 Dyer S, Mokoena N, Maritz J, van der Spuy Z. Motives for parenthood among couples attending a level 3 infertility clinic in the public health sector in South Africa. Hum Reprod 2008; 23: 353-7.

10 Fisher J, Baker H, Hammarberg K. Long-term health, well-being, life satisfaction, and attitudes towards parenthood in men diagnosed as infertile: challenges to gender stereotypes and implications for practice. Fertil Steril 2010; 94: 574-80.

11 van Balen F, Trimbos-Kemper TC. Involuntary childless couples: their desire to have children and their motives. J Psychosom Obst Gynaecol 1995; 16: 137-44.
12 Dudgeon MR, Inhorn MC. Gender, masculinity and reproduction: anthropological perspectives. Int J Men's Health 2003; 2: 31-56.

13 Gannon K, Glover L, Abel PD. Masculinity, infertility, stigma and media reports. Soc Sci Med 2004; 59: 1169-75.

14 Anderson KM, Sharpe M, Rattray A, Irvine DS. Distress and concerns in couples referred to a specialist infertility clinic. J Psychosom Res 2003; 54: 353-5.

15 Beaurepaire J, Jones M, Thiering P, Saunders D, Tennant C. Psychosocial adjustment to infertility and its treatment: male and female responses at different stages of IVF/ET treatment. J Psychosom Res 1994; 38: 229-40.

16 Edelmann RJ, Connolly KJ. Gender differences in response to infertility and infertility investigation: real or illusory. Br J Health Psychol 2000; 5: 365-75.

17 Zorn B, Auger J, Velikonja V, Kolbezen M, Meden-Vrtovec H. Psychological factors in male partners of infertile couples: relationship with semen quality and early miscarriage. Int J Androl 2007; 31: 557-64.

18 Klemetti R, Raitanen J, Sihvo S, Saarni S, Koponen P. Infertility, mental disorders and well-being: a nationwide survey. Acta Obstet Gynecol Scand 2010; 89: 677-82.

19 Peterson BD, Newton CR, Rosen KH, Skaggs GE. Gender differences in how men and women who are referred to IVF cope with infertility stress. Hum Reprod 2006; 21 : 2443-9.

20 Wichman C, Ehlers S, Wichman S, Weaver A, Coddington C. Comparison of multiple psychological distress measures between men and women preparing for in vitro fertilization. Fertil Steril 2011; 95: 717-21.

21 Chachamovich JR, Chachamovich E, Ezer H, Fleck MP, Knauth D et al. Investigating quality of life and health-related quality of life in infertility: a systematic review. J Psychosom Obstet Gynaecol 2010; 31: 101-10.

22 Radloff LS. The CES-D scale: a self-report depression scale for research in the general population. App/ Psychol Meas 1977; 1: 385-401.

23 Spielberger CD, Gorsuch RL, Lushene RE. The State-Trait Anxiety Inventory: Test Manual. Palo Alto, CA: Consulting Psychologists Press; 1983.

24 Beck AT, Ward CH, Mendelson M, Mock JE, Erbaugh J. An inventory for measuring depression. Arch Gen Psychiatry 1961; 4: 561-71.

25 Zigmond AS, Snaith RP. The Hospital Anxiety and Depression Scale. Acta Psychiatr Scand 1983; 67: 361-70.

26 Horowitz M, Wilner N, Alvarez W. Impact of events scale: a measure of subjective distress. Psychosom Med 1979; 41: 209-18.

27 Newton CR, Sherrard W, Glavac I. The fertility problem inventory: measuring perceived infertility-related stress. Fertil Steril 1999; 72: 54-62.

28 Hjelmstedt A, Andersson L, Skoog-Svanberg A, Bergh T, Boivin J et al. Gender differences in psychological reactions to infertility among couples seeking IVF- and ICSI-treatment. Acta Obstet Gynecol Scand 1999; 78: 42-8.

29 Robins LN, Wing J, Wittchen HU, Helzer JE. The Composite International Diagnostic Interview: an epidemiologic instrument suitable for use in conjunction with different diagnostic systems and in different cultures. Arch Gen Psychiatry 1988; 45: 106977.

30 Goldberg D. General Health Questionnaire (GHQ-12). Windsor: NFER-Nelson; 1992.

31 Glover L, Gannon K, Sherr L, Abel PD. Psychological distress before and immediately after attendance at a male sub-fertility clinic. J Roy Soc Med 1994; 87: 448-9.

32 Zung WW. A rating instrument for anxiety disorders. Psychosomatics 1971; 7: 371-9.

33 World Health Organization. Info Package: Mastering Depression in Primary Care, Version 2.2. Fredriksborg: WHO, Regional Office for Europe; 1999; 1-11.

34 Holter H, Anderheim L, Bergh C, Möller A. The psychological influence of gender infertility diagnoses among men about to start IVF or ICSI treatment using their own sperm. Hum Reprod 2007; 22: 2559-65.

35 Dupuy HJ. The Psychological General Well-Being (PGWB) index. In: Wenger NK, Mattson ME, Furber CF, Ellison J, editors. Assessment of Quality of Life in Clinical Trials of Cardiovascular Therapies. New York: Le Jack Publications Inc.; 1984; p17083.

36 Nachtigall RD, Becker G, Wozny M. The effect of gender-specific diagnosis on men's and women's response to infertility. Fertil Steril 1992; 57: 113-21.

37 Abbey A, Andrews FM, Halman JL. Gender's role in responses to infertility. Psychol Women Q 1991; 15: 295-316.

38 Ware JE, Snow GKK, Kosinski M, Gandek B. SF-36 Health Survey Manual and Interpretation Guide. Boston, MA: New England Medical Centre, The Health Institute; 1993.

39 Peronace LA, Boivin J, Schmidt L. Patterns of suffering and social interactions in infertile men: 12 months after unsuccessful treatment. J Psychosom Obstet Gynecol 2007; 28: 105-14.

40 Lee TY, Sun GH, Chao SC. The effect of an infertility diagnosis on the distress, marital and sexual satisfaction between husbands and wives in Taiwan. Hum Reprod 2001; 16: $1762-7$.

41 Lee SH, Kuo BJ, Lee MC. Psychosocial responses of Chinese infertile couples attending an assisted reproduction program. J Formosan Med Assoc 1995; 94: 2633.

42 Smith JF, Walsh TJ, Shindel AW, Turek PJ, Wing H et al. Sexual, marital and social impact of a man's perceived infertility diagnosis. J Sex Med 2009; 6: 2505-15.

43 Dhillon R, Cumming CE, Cumming DC. Psychological well-being and coping patterns in infertile men. Fertil Steril 2000; 74: 702-6.

44 McCubbin HI, Patterson JM, Wilson LR. Family Inventory of Life Events and Changes. St Paul, MN: Medical Education and Research; 1981.

45 Drosdzol A, Skrzypulex V. Depression and anxiety among Polish infertile couples_and evaluative prevalence study. J Psychosom Obstet Gynaecol 2009; 30: 11-20. 
46 Tüzer V, Tuncel A, Göka S, Dogan Bulut S, Yüksel F et al. Marital adjustment and emotional symptoms in infertile couples: gender differences. Turk J Med Sci 2010 40: 229-37.

47 Band DA, Edelmann RJ, Avery S, Brinsden PR. Correlates of psychological distress in relation to male infertility. Br J Health Psychol 1998; 3: 245-56.

48 Cohen S, Kamarck T, Mermelstein R. A global measure of perceived stress. $J$ Health Soc Behav 1983; 24: 385-96.

49 Folkman S, Lazarus RS, Dunkel-Schetter C, DeLongis A, Gruen R. The dynamics of a stressful encounter: cognitive appraisal, coping, and encounter outcomes. J Pers Soc Psychol 1986; 50: 992-1003.

50 Jordan C, Revenson TA. Gender differences in coping with infertility: a meta-analysis. J Behav Med 1999; 22: 341-58.

51 Inhorn MC. Masturbation, semen collection and men's IVF experiences: anxieties in the Muslim world. Body Soc 2007; 13: 37-53.

52 Fisher JR. Infertility and Assisted Reproduction. In World Health Organization. Mental Health Aspects of Women's Reproductive Health. A Global Review of the Literature. Geneva, World Health Organization and United Nations Population Fund 2009; p12846.

53 Umeora OU, Ejikeme BN, Sunday-Adeoye I, Umeora MC. Sociocultural impediments to male factor infertility evaluation in rural South-east Nigeria. J Obstet Gynaecol 2008; 28: 323-6.

54 Dhont M, Luchters S, Ombelet W, Vyankandondera J, Gasarabwe A et al. Gender differences and factors associated with treatment-seeking behaviour for infertility in Rwanda. Hum Reprod 2010; 25: 2024-30.

55 Dhont N, van de Wijgert J, Coene G, Gasarabwe A, Temmerman M. Mama and papa nothing: living with infertility among an urban population in Kigali, Rwanda. Hum Reprod 2011; 26: 623-9.

56 Folkvord S, Odegaard OA, Sundby J. Male infertility in Zimbabwe. Patient Educ Couns 2005; 59: 239-43.

57 Nieuwenhuis SL, Odukogbe AT, Theobald S, Liu X. The impact of infertility on infertile men and women in Ibadan, Oyo State, Nigeria: a qualitative study. Afr J Reprod Health 2009; 13: 85-98.

58 Dyer SJ, Abrahams N, Mokoena NE, van der Spuy ZM. You are a man because you have children: experiences, reproductive health knowledge and treatment seeking behaviour among men suffering from couple infertility in South Africa. Hum Reprod 2004; 19: 960-7.

59 Dyer S, Lombard C, van der Spuy Z. Psychological distress among men suffering from couple infertility in South Africa: a quantitative assessment. Hum Reprod 2009; 24 2821-6.

60 Derogatis L, Lipman R, Rickels K. The Hopkins Symptom Checklist: a self-report symptom inventory. Behav Sci 1974; 19: 1.

61 Hunt N, McHale S. Psychosocial aspects of andrologic disease. Endocrinol Metabo Clin N Am 2007; 36: 521-31.

62 Müller MJ, Schilling G, Haidl G. Sexual satisfaction in male infertility. Arch Androl 1999; 42: 137-43.

63 Ramezanzadeh F, Aghssa MM, Jafarabadi M, Zayeri F. Alterations of sexual desire and satisfaction in male partners of infertile couples. Fertil Steril 2006; 85: 139-43.

64 Spanier GB. Measuring dyadic adjustment: new scales for assessing the equality of marriage and similar dyads. J Marriage Fam 1976; 38: 15.

65 Hammarberg K, Baker HGW, Fisher J. Men's experiences of infertility and infertility treatment 5 years after diagnosis of male factor infertility: a retrospective cohort study. Hum Reprod 2010; 25: 2815-20.

66 Schmidt L, Holstein B, Christensen U, Boivin J. Does infertility cause marital benefit? An epidemiological study of 2250 women and men in fertility treatment. Patient Edu Couns 2005; 59: 244-51.
67 Dancet EA, Nelen WL, Sermeus W, de Leeuw L, Kremer JA et al. The patients' perspective on fertility care: a systematic review. Hum Reprod Update 2010; 16 467-87.

68 Dancet EA, Spiessens C, Blocquiaux L, Sermeus W, Vanderschuerem D et al. Testicular biopsy before ART: the patients' perspective on the quality of care. Hum Reprod 2010; 25: 3072-82.

69 van Empel I, Nelen W, Tepe E, van Laarhoven E, Veerhaak C et al. Weaknesses, strengths and needs in fertility care according to patients. Hum Reprod 2010; 25 142-9.

70 Pook M, Krause W, Drescher S. Distress of infertile males after fertility workup: a longitudinal study. J Psychosom Res 2002; 53: 1147-52.

71 Pook M, Krause W. The impact of treatment experiences on the course of infertility distress in male patients. Hum Reprod 2005; 20: 825-8.

72 Schmidt L, Holstein BE, Boivin J, Tiørnhøj-Thomsen T, Blaabjerg J et al. High ratings of satisfaction with fertility treatment are common: findings from the Copenhagen Multi-centre Psychosocial Infertility (COMPI) Research Programme. Hum Reprod 2003; 18: 2638-46.

73 Agostini F, Monti F, De Pascalis L, Paterlini M, La Sala GB et al. Psychosocial suport for infertile couples during assisted reproductive technology treatment. Fertil Steri 2011; 95: 707-10.

74 Zimet GD, Dahlem NW, Zimet SG, Farley GK. The Multidimensional Scale of Perceived Social Support. J Pers Assess 1988; 52: 30-41.

75 Lee TY, Chu TY. The Chinese experience of male infertility. West J Nurs Res 2001; 23 714-25.

76 Malik S, Coulson N. The male experience of infertility: a thematic analysis of an online infertility support group bulletin board. J Reprod Infant Psychol 2008; 26: 18-30.

77 Brucker PS, McKenry PC. Support from health care providers and the psychological adjustment of individuals experiencing infertility. J Obstet Gynecol Neonatal Nurs 2004; 33: 597-603.

78 Laffont I, Edelmann RJ. Perceived support and counselling needs in relation to in vitro fertilization. J Psychosom Obstet Gynaecol 1994; 15: 183-8.

79 Schmidt L, Holstein BE, Boivin J, Sangren H, Tjørnhøj-Thomsen T et al. Patients' attitudes to medical and psychosocial aspects of care in fertility clinics: findings from the Copenhagen Multi-centre Psychosocial Infertility (COMPI) research programme. Hum Reprod 2003; 18: 628-37.

80 Boivin J, Scanlan L, Walker SM. Why are infertile couples not using psychosocial counselling? Hum Reprod 1999; 14: 1384-91.

81 Wischmann T, Scherg H, Strowitski T, Verres R. Psychosocial characteristics of women and men attending infertility counselling. Hum Reprod 2009; 24: 378-85.

82 Furman I, Parra L, Fuentes A, Devoto L. Men's participation in psychologic counseling services offered during in vitro fertilization. Fertil Steril 2010; 94: 1460-4.

83 Throsby K, Gill R. "It's different for men" masculinity and IVF. Men Masculin 2004, 6: $330-48$.

84 Sherrod RA. Male infertility: the element of disguise. J Psychosoc Nurs Men Health Serv 2006; 44: 30-7.

85 Wilhelm K, Parker G. The development of a measure of intimate bonds. Psychol Med 1988; 18: 225-34.

86 Diener E, Emmons RA, Larson RJ, Griffin S. The Satisfaction with Life Scale. J Pers Assess 1985; 49: 71-6.

87 Ware JE, Kosinski M, Keller SD. A 12-item short-form health survey: construction of scales and preliminary results of reliability and validity. Med Care 1996; 34: 220-33.

88 Eisenberg ML, Smith JF, Millstein SG, Walsh TJ, Breyer BN et al. Perceived negative consequences of donor gametes from male and female members of infertile couples. Fertil Steril 2010; 94: 921-6. 